\title{
Preparation and Performance of an Estradiol Templated Magnetic Sphere of Molecularly Imprinted Cryogel
}

\author{
Jian Wang, Lili Tian, Yanan Yan, Yaru Liu, Yan Zhang and Chun Yang* \\ School of Chemistry and Chemical Engineering, Yangzhou University, 225002 Yangzhou, China
}

\begin{abstract}
An estradiol templated core-shell magnetic molecularly imprinted cryogel (MMIC) was synthesized to selectively extract and analyze estradiol in milk powder. The microsphere of $\mathrm{Fe}_{3} \mathrm{O}_{4} @ \mathrm{SiO}_{2}$ was firstly prepared on $\mathrm{Fe}_{3} \mathrm{O}_{4}$ with ethyl silicate and 3-methyl propyl trimethoxy silane. Then the polymerization of $\alpha$-methacrylic acid and ethylene glycol dimethyl acrylate was carried out on $\mathrm{Fe}_{3} \mathrm{O}_{4} @ \mathrm{SiO}_{2}$ at $-20{ }^{\circ} \mathrm{C}$ for $24 \mathrm{~h}$ with estradiol as template. The morphology and microstructure of MMIC were investigated by transmission electron microscopy and infrared spectrogram. When used as chromatographic stationary phase, MMIC showed good selectivity and chromatographic performance for the template. Spiked milk powder samples were used to examine the adsorption capacity and selectivity of MMIC, giving recoveries of 92-101\% and limit of detection $0.8-1.2 \mathrm{ng} \mathrm{g}^{-1}$. Experimental results indicate good reproducibility with relative standard deviation from 2.2 to $4.5 \%(\mathrm{n}=3)$ at spiked levels of estradiol 10, 50, and $100 \mathrm{ng} \mathrm{g}^{-1}$.
\end{abstract}

Keywords: magnetic sphere, molecularly imprinted cryogel, estradiol, milk powder

\section{Introduction}

Sample preparation is of vital importance in an analysis for reducing the interference of impurities, concentrating the low abundant components, and improving the sensitivity and selectivity. Sample pretreatment occupies more than $60 \%$ of the entire time, while it presents poor reproducibility and accuracy. Thus, a sound sample pretreatment is crucial to guarantee the accuracy, reliability of the results, as well as the efficiency of analytical determination. ${ }^{1}$

Solid phase extraction (SPE) has widely been used in the extraction, purification, and enrichment of analytes in environmental, food, and biological samples. However, SPE cannot eliminate the interference of matrix in complex samples because the conventional adsorbents, such as normal, reverse, and ionic phase and other special adsorbents, have poor selectivity. Molecularly imprinted polymer (MIP) is a kind of inclusive compound prepared from template, monomer, and cross linker. There is a covalent bond or hydrogen bond or Van der Waals' force between template and polymer. ${ }^{2}$ When template molecule is removed, a specific cavity with binding sites complementary to the size, shape, and functional group of template is formed in the polymer. ${ }^{2}$ Molecularly imprinted

*e-mail: cyang01@126.com polymers based solid phase extraction (MIP-SPE) can be implemented in selective separation, analysis, and preparation of high-purity target substance. MIP-SPE can achieve rapid and high efficiency of extraction of the analytes, because of high specific surface area and high mass transfer rate. ${ }^{3,4}$

Core-shell magnetic molecularly imprinted polymer (MMIP) is a new type of functional composite, the magnetic core (such as $\mathrm{Fe}_{3} \mathrm{O}_{4}$ ) of which is covered with inorganic $\left(\mathrm{SiO}_{2}, \mathrm{Al}_{2} \mathrm{O}_{3}\right.$, etc.) or organic (surfactant, polymer, etc.) layers. ${ }^{5-7}$ The layer can be further modified with hydrophilic and/or biocompatible functional groups, including $\mathrm{C}=\mathrm{C}$, $-\mathrm{NH}-,-\mathrm{Br}$ and sulfonyl, then dipole interaction of core is shielded, and agglomeration of particles is prevented. ${ }^{3,8-10}$ Core-shell MMIP can provide specific recognition because of the mesoporous and microporous molecular scale cavities, and can shorten the processing time of sample due to the excellent settling performance and ease to be separated from the matrix through an external magnetic field. ${ }^{11}$ Core-shell MMIP can increase the contact area of adsorbent and matrix, and thus provide a larger diffusion and mass transfer rate due to its good dispersion. ${ }^{12} \mathrm{Fe}_{3} \mathrm{O}_{4}$ cored core-shell MMIP has been widely applied in solid phase extraction, drug delivery, enzyme immobilization, cell imaging, proteomics, DNA sequencing, bio magnetic separation, immunomagnetic separation, etc. ${ }^{13,14}$ 
Some functional groups modified core-shell MMIP meet the requirements of a chromatographic stationary phase, and have been applied in capillary electrophoresis and chromatographic separation. ${ }^{15,16}$ Zhu et al. ${ }^{17}$ used $\mathrm{Fe}_{3} \mathrm{O}_{4} @ \mathrm{SiO}_{2}-\mathrm{NH}_{2}$ magnetic nanoparticles as stationary phase in capillary electrochromatography. The column efficiency was evaluated with five organic acids and the relative column efficiency of ortho amino benzoic acid was 220,000 plates $\mathrm{m}^{-1}$. Yan et al. ${ }^{18}$ prepared core shell magnetic $\mathrm{SiO}_{2}$-UIO-66 and used it as stationary phase in liquid chromatography. The packed column was applied to the rapid and efficient separation of isomers, including toluene and xylene, chlorotoluenes, ethylbenzene and xylene. Qin et al. ${ }^{19}$ prepared core shell magnetic silica microparticle with $\mathrm{COOH}$-terminated surface through liquid phase epitaxy, and used it as a stationary phase for separation of isomers, such as pyridine and 4,4'-bipyridine, and chloroaniline by size exclusion chromatography.

Cryogels are cryogenically polymerized macroporous material. ${ }^{20}$ The super macroporous structure in cryogel leads to a very low mass transfer resistance, and facilitates optional modifications on its surface to satisfy various research purposes. ${ }^{21}$ Molecularly imprinted cryogels (MICs) integrate fast mass transfer, high selectivity and suitable affinity toward specific targeted molecules. ${ }^{22}$ MICs have been widely used in the fields of bioanalysis and bioengineering to deal with peptides, proteins, nucleic acids, virus particles, organelle, cell and microorganism. ${ }^{23-27}$ Additionally, a modified MIC has been used to catalyze the production of biodiesels. ${ }^{28}$ Various molecular imprinting strategies, including mixed template, dummy template, pending template, have been utilized in the synthesis of MICs with different template molecules..$^{29-32}$

Synthetic estrogens, such as estradiol (E2), show strong endocrine disruption impacts on the hormone balance in an organism even under extremely low concentrations, due to their similar biological effects to that of endogenous hormones. ${ }^{33,34}$ Estrogen can enter and store in the human body through the food chain and cause toxic and side effects. ${ }^{35}$ Abuse of estrogens will cause abnormal sex, short growth cycle, feminization and sexual precocity of animals and human. ${ }^{36-38}$ In production of raw milk, farmers may use illegally antibiotics and hormones to increase milk production. The aim of determine estrogens in raw milk and dairy products is to monitor milk production. Estrogens have been detected by gas chromatography-mass spectrometry (GC-MS), liquid chromatography-mass spectrometry (LC-MS), high-performance liquid chromatography tandem mass spectrometry (HPLC-MS/MS), fluorescence quenching, and surface enhanced Raman spectroscopy. ${ }^{39-43}$ Estrogens have been extracted by cloud point, membrane assisted liquid-liquid extraction, solid phase extraction, and solid phase microextraction (SPME) $)^{44-47}$ from water, silt, animal tissues, and aquatic products. ${ }^{48}$ Stir bar, dispersive liquid-liquid microextraction, and ultrasound-assisted surfactant-enhanced emulsification microextraction have also been employed in extracting estrogen. ${ }^{49-51}$ Extraction of estrogen in infant milk powder by core-shell MIC has not been reported previously.

In the present paper, spherical core-shell magnetic $\mathrm{Fe}_{3} \mathrm{O}_{4} @ \mathrm{SiO}_{2} @ \mathrm{MIC}$ with $\mathrm{E} 2$ as template was prepared through coating MIC on magnetic microparticles via cryogenical free radical polymerization. The prepared $\mathrm{Fe}_{3} \mathrm{O}_{4} @ \mathrm{SiO}_{2} @ \mathrm{MIC}$ was utilized in the selective extraction of E2 from infant formula milk powder. Magnetic substrate was first modified with $\mathrm{SiO}_{2}$ and then grafted with vinyl end groups. Cryogenical polymerization was performed via copolymerization of vinyl group with functional monomer and cross linker in the presence of target molecule at $-20{ }^{\circ} \mathrm{C}$. The results verified that the present $\mathrm{Fe}_{3} \mathrm{O}_{4} @ \mathrm{SiO}_{2} @ \mathrm{MIC}$ was applicable to the detection of $\mathrm{E} 2$ from infant formula milk powder.

\section{Experimental}

\section{Reagents and equipments}

$\mathrm{FeCl}_{3} \cdot 6 \mathrm{H}_{2} \mathrm{O}$ was analytical reagent $(\mathrm{AR})$ and purchased from Aladdin, China. 3-Methyl propyl trimethoxy silane (MPS, AR) was purchased from Nanjing Daoning Chemical Co. Ltd., China. E2 and estriol (98\%) were obtained from Adamas Reagent, Ltd., China. Methyl acrylic acid (MAA) was chemically pure (CP) and obtained from Shanghai Ling Feng Chemical Reagent Co., Ltd., China. Ethylene glycol dimethyl acrylate (EGDMA, AR) was from Alfa Aesar, China. Azobisisobutyronitrile (AIBN, $\mathrm{CP}$ ) and tetraethoxysilane (TEOS, AR) were purchased from Shanghai NO. 4 Reagent \& H. V. Chemical, Co., Ltd., China. Anhydrous sodium acetate (NaAc, AR), Tween-20 (CP), ammonium persulfate (APS, AR), sodium hydrogen sulfite (SBS, AR), methanol (guaranteed reagent), acetonitrile (AR), $n$-hexane (AR), ethanol (AR), acetone (AR) and potassium bromide (AR) were purchased from Sinopharm Chemical Reagent Co., Ltd., China.

\section{Methods}

The infrared absorption spectrogram of $\mathrm{Fe}_{3} \mathrm{O}_{4} @ \mathrm{SiO}_{2} @ \mathrm{MIC}$ was recorded on Fourier transform infrared (FTIR) spectrometer (Tensor 27, Bruker, Germany). The absorption of E2 in solution was measured with a UV-Vis spectrophotometer (UV-2550, Shimadzu, Japan). The morphology and structure of magnetic molecularly imprinted cryogel (MMIC) were 
investigated by transmission electron microscopy (TEM, Tecnai 12, Philips, Netherlands) and X-ray diffraction (XRD, D8 ADVANCE, Bruker, Germany). HPLC analysis was performed on an Agilent 1200 HPLC comprising of a G1311A quaternary pump module, a G1329A autosampler and a G1315D diode-array detector (DAD). The mobile phases were methanol and water of different volume ratios at a flow rate of $0.8 \mathrm{~mL} \mathrm{~min}{ }^{-1}$. Separation was performed in a $\mathrm{C}_{18}$ column $(150 \times 4.6 \mathrm{~mm}$, Inertsil, GL Sciences, Japan $)$ or a packed column at room temperature $\left(25^{\circ} \mathrm{C}\right) .20 \mu \mathrm{L}$ of solution was injected into the columns for each analysis on DAD at $280 \mathrm{~nm}$.

In real sample analysis, the samples of milk powder was preprocessed by liquid-liquid extraction, and extracted with MMIC after spiked with E2. The filter liquors before and after extraction were analyzed by HPLC.

\section{Preparation of $\mathrm{Fe}_{3} \mathrm{O}_{4}$ microparticles}

The $\mathrm{Fe}_{3} \mathrm{O}_{4}$ magnetic microparticles were prepared from $1.35 \mathrm{~g} \mathrm{FeCl}_{3} \cdot 6 \mathrm{H}_{2} \mathrm{O}, 3.60 \mathrm{~g} \mathrm{NaAc}$ and $40 \mathrm{~mL}$ ethylene glycol in a sealed high pressure reactor at $200{ }^{\circ} \mathrm{C}$ for $8 \mathrm{~h}$, according to the method in literature. ${ }^{21}$

Preparation of double bond silanized magnetic microparticles of $\mathrm{Fe}_{3} \mathrm{O}_{4} @ \mathrm{SiO}_{2}$

$0.1 \mathrm{~g}^{\mathrm{Fe}_{3} \mathrm{O}_{4}}$ was dispersed in a solution $\left(\mathrm{C}_{2} \mathrm{H}_{2} \mathrm{OH}: \mathrm{H}_{2} \mathrm{O}: \mathrm{NH}_{3} \cdot \mathrm{H}_{2} \mathrm{O}\right.$ 80:20:1 v/v/v) after it was ultrasonically washed in $\mathrm{HCl}\left(0.1 \mathrm{~mol} \mathrm{~L}^{-1}\right)$ and water. The mixture was magnetically stirred at room temperature for $6 \mathrm{~h}$ after $0.75 \mathrm{~mL}$ TEOS was dropped into it. Then black $\mathrm{Fe}_{3} \mathrm{O}_{4} @ \mathrm{SiO}_{2}$ microparticles were prepared after the lower solid was consecutively separated from liquid under an external magnetic field, washed with ethanol, and dried at $50{ }^{\circ} \mathrm{C}$ in a vacuum.

The mixture of $0.1 \mathrm{~g} \mathrm{Fe}_{3} \mathrm{O}_{4} @ \mathrm{SiO}_{2}$ in $30 \mathrm{~mL} \mathrm{C}_{2} \mathrm{H}_{2} \mathrm{OH}$ was stirred for $24 \mathrm{~h}$ at room temperature after $3 \mathrm{~mL}$ MPS was dropped into it. The lower solid was magnetically separated from the upper liquid and washed with $\mathrm{CH}_{3} \mathrm{OH}$ to remove the residual MPS. Double bond silanized $\mathrm{Fe}_{3} \mathrm{O}_{4} @ \mathrm{SiO}_{2}$ magnetic microparticles were obtained after the solid was dried at $50{ }^{\circ} \mathrm{C}$ in a vacuum.

\section{Preparation of MMIC}

A pre-reaction was carried out for $3 \mathrm{~h}$ at $-20^{\circ} \mathrm{C}$ in $2 \mathrm{~mL}$ acetone comprising $0.055 \mathrm{~g}$ E2 and $0.075 \mathrm{~mL}$ MAA. The prepolymerized pMAA containing E2, $0.050 \mathrm{~g}$ double bond silanized $\mathrm{Fe}_{3} \mathrm{O}_{4} @ \mathrm{SiO}_{2}, 0.660$ mLEGDMA, and Tween 20 were ultrasonically dispersed evenly in $40 \mathrm{~mL}$ water. After the mixture was emulsified completely, $0.028 \mathrm{~g} \mathrm{SBS}$ and $0.086 \mathrm{~g}$ APS were ultrasonically dissolved in it evenly.

The crosslinking reaction was conducted at $-20{ }^{\circ} \mathrm{C}$ for $24 \mathrm{~h}$ in a zip lock bag. The prepared cryogel was thawed at $60{ }^{\circ} \mathrm{C}$ in a water bath and the surplus water was removed by pump filtration afterwards. E2 was eliminated by a mixed solution of methanol and HAc $(9: 1 \mathrm{v} / \mathrm{v})$. The magnetic microparticles MMIC were prepared ultimately after the solid remainder was dried at $50^{\circ} \mathrm{C}$. The complete route for preparing MMIC was illustrated in Figure 1.

For comparison, the MNIC (magnetic non-imprinted cryogel) was prepared in a similar route as that for preparing MMIC, without E2 molecules. Meanwhile, the E2 templated MIC was prepared in a similar route, without double bond silanized $\mathrm{Fe}_{3} \mathrm{O}_{4} @ \mathrm{SiO}_{2}$ as the core.

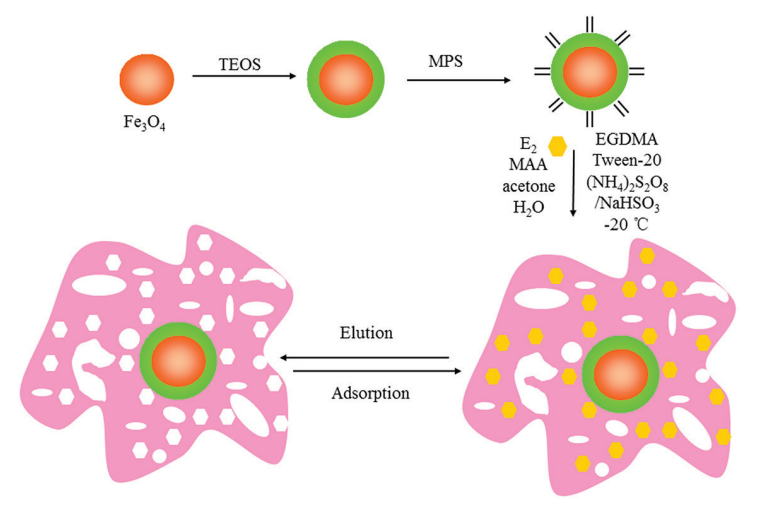

Figure 1. Synthetic route of estradiol templated MMIC.

Preparation of MMIP

$0.075 \mathrm{~mL}$ MAA was prepolymerized with $0.055 \mathrm{~g} \mathrm{E} 2$ in $20 \mathrm{~mL}$ solution of acetonitrile and toluene $(3: 1 \mathrm{v} / \mathrm{v})$ for $3 \mathrm{~h}$ at room temperature. Afterwards, $0.05 \mathrm{~g} \mathrm{Fe}_{3} \mathrm{O}_{4} @ \mathrm{MPS}$, $0.66 \mathrm{~mL}$ EGDMA, $40 \mathrm{mg}$ AIBN were ultrasonically dispersed evenly in another $20 \mathrm{~mL}$ solution of acetonitrile and toluene $(3: 1 \mathrm{v} / \mathrm{v})$. The two aliquots of mixture were mixed together and the crosslinking reaction was carried out at $60{ }^{\circ} \mathrm{C}$ for $24 \mathrm{~h}$. The lower solid was magnetically separated from the liquid and washed with methanol after ageing at $80{ }^{\circ} \mathrm{C}$ for $3 \mathrm{~h}$. E2 was removed by the solution $\left(\mathrm{CH}_{3} \mathrm{OH}: \mathrm{HAc}\right.$ 9:1 v/v) and MMIP was prepared after the solid remainder was dried. MNIP (magnetic non-imprinted polymer) was prepared in a similar route as that for preparing MMIP, without E2.

\section{Results and Discussion}

Preparation conditions

The highest yield of MMIC could be achieved while 
the molar ratio of E2:MAA:EGDMA was 1:4:16. When $0.05 \mathrm{~g}$ E2 was placed in $2 \mathrm{~mL}$ acetonitrile, dioxane and acetone, E2 could hardly dissolve in acetonitrile. E2 dissolved completely in dioxane, however, the packed column with the prepared E2 templated MMIC as stationary phase tended to be blocked. E2 was readily dissolved in acetone, and the pressure of the MMIC packed column was still lower than 10 bars within $36 \mathrm{~h}$. Therefore, acetone was chosen as the solvent of E2.

\section{Characterization of MMIC}

\section{TEM}

From Figure 2, the well dispersed $\mathrm{Fe}_{3} \mathrm{O}_{4}$ microparticles were uniformly $500 \mathrm{~nm}$. The diameter of the finally prepared MMIC particles increased to about three times as much as that of $\mathrm{Fe}_{3} \mathrm{O}_{4}$. From Figure 2e, MMIC particles had obvious core-shell structure and larger cavities on the surface of it, which was formed during the polymerization at $-20{ }^{\circ} \mathrm{C}$. The core-shell structure of MMIC particles could not only increase the mass transfer rate between the solution and the surfaces of particles, but also could increase the hardness of the organic-inorganic hybrid material. It was advantageous for a good chromatographic behavior of MMIC when it was packed in a column as a stationary phase in HPLC.

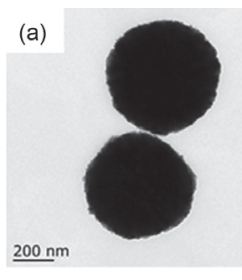

(b)

$\underline{200 \mathrm{~nm}}$

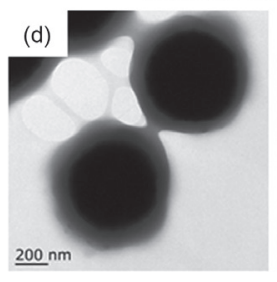

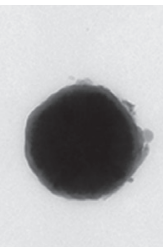

(c)
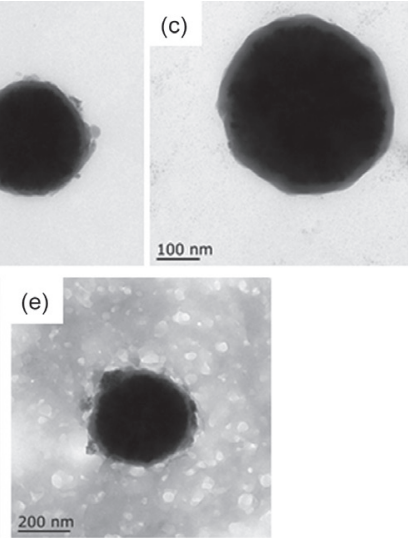

Figure 2. TEM images of (a) $\mathrm{Fe}_{3} \mathrm{O}_{4}$; (b) $\mathrm{Fe}_{3} \mathrm{O}_{4} @ \mathrm{SiO}_{2}$; (c) $\mathrm{Fe}_{3} \mathrm{O}_{4} @ \mathrm{MPS}$; (d) MMIP and (e) MMIC.

\section{FTIR}

In Figure 3, the stretching vibration peaks at $769 \mathrm{~cm}^{-1}$ of $\mathrm{Si}-\mathrm{O}$ and $1082 \mathrm{~cm}^{-1}$ of $\mathrm{Si}-\mathrm{O}-\mathrm{Si}$ suggested the successful silicon alkylation on the surfaces of $\mathrm{Fe}_{3} \mathrm{O}_{4}$ particles. The sharp peak at $1631 \mathrm{~cm}^{-1}$ of $\mathrm{C}=\mathrm{C}$ showed that MPS had been successfully modified on the silanized magnetic microparticles, which would provide a large number of reactive sites for the subsequent polymerization. The stretching vibration peaks of $\mathrm{C}=\mathrm{O}$ at $1728 \mathrm{~cm}^{-1}$ and $\mathrm{C}=\mathrm{C}$ at $2949 \mathrm{~cm}^{-1}$ were of MMIP, while the peaks of $\mathrm{C}=\mathrm{O}$ at
$1730 \mathrm{~cm}^{-1}$ and $\mathrm{C}=\mathrm{C}$ at $2927 \mathrm{~cm}^{-1}$ were of MMIC. These illustrated that MAA had been grafted on the surface of Fe3O4@MPS, as well as that the surfaces of the magnetic $\mathrm{Fe}_{3} \mathrm{O}_{4} @ \mathrm{SiO}_{2}$ particles had been modified successfully with a MIC layer.

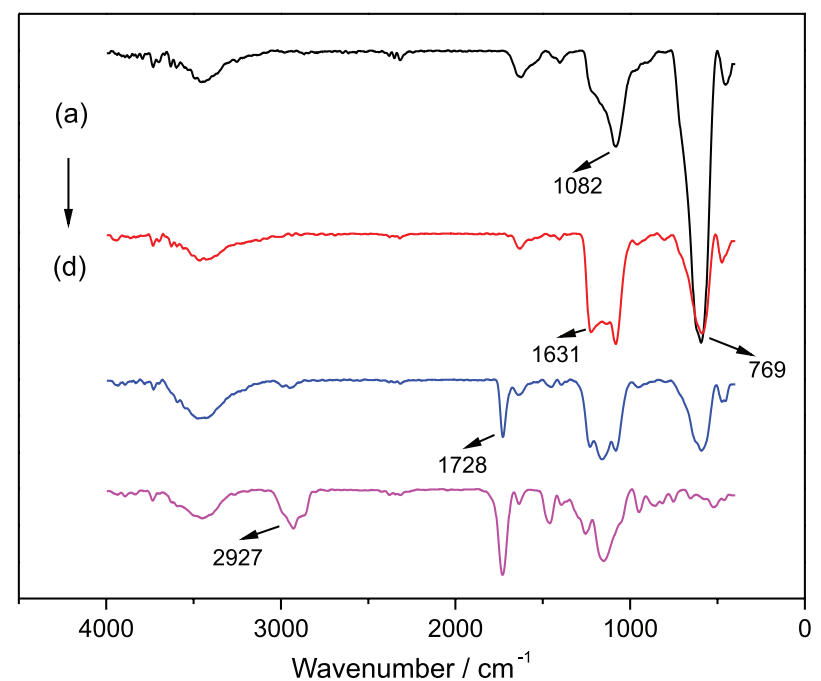

Figure 3. FTIR images of (a) $\mathrm{Fe}_{3} \mathrm{O}_{4} @ \mathrm{SiO}_{2}$; (b) $\mathrm{Fe}_{3} \mathrm{O}_{4} @ \mathrm{MPS}$; (c) MMIP and (d) MMIC.

\section{XRD}

Figure 4 showed that all the XRD curves of $\mathrm{Fe}_{3} \mathrm{O}_{4}$, $\mathrm{Fe}_{3} \mathrm{O}_{4} @ \mathrm{SiO}_{2}, \mathrm{Fe}_{3} \mathrm{O}_{4} @ \mathrm{MPS}, \mathrm{MMIP}$ and MMIC presented the six characteristic peaks $(2 \theta)$ of $30.2^{\circ}, 35.6^{\circ}, 43.2^{\circ}$, $53.6^{\circ}, 57.2^{\circ}$, and $62.8^{\circ}$. These peaks corresponded to the crystal face index of (220), (311), (400), (422), (511), and (440) of $\mathrm{Fe}_{3} \mathrm{O}_{4}$ in XRD standard card (JCPDS: 19-629). These XRD data stated that the prepared magnetic microparticles of $\mathrm{Fe}_{3} \mathrm{O}_{4} @ \mathrm{SiO}_{2}, \mathrm{Fe}_{3} \mathrm{O}_{4} @ \mathrm{MPS}, \mathrm{MMIP}$ and MMIC kept fine crystal structures consistent with that of

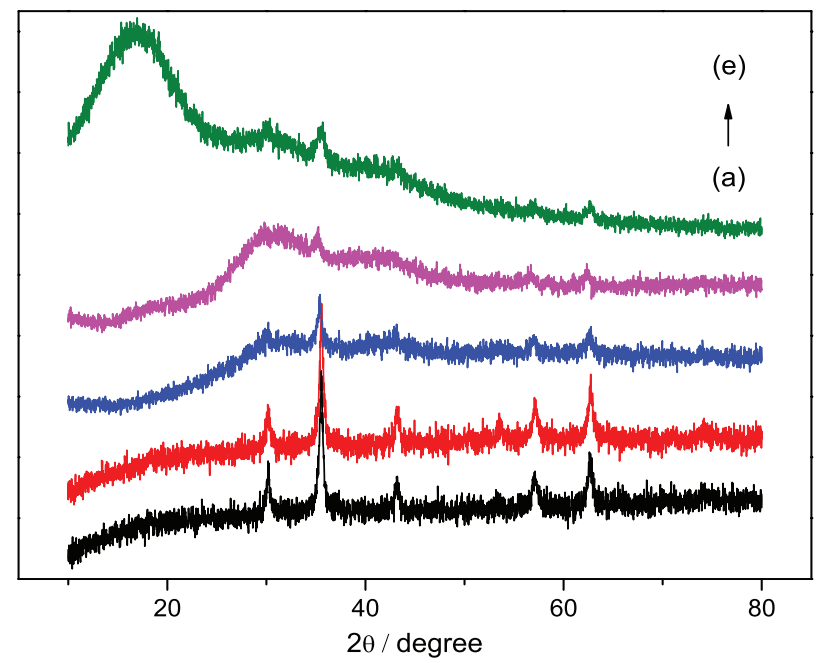

Figure 4. XRD images of (a) $\mathrm{Fe}_{3} \mathrm{O}_{4}$; (b) $\mathrm{Fe}_{3} \mathrm{O}_{4} @ \mathrm{SiO}_{2}$; (c) $\mathrm{Fe}_{3} \mathrm{O}_{4} @$ MPS; (d) MMIP and (e) MMIC. 
$\mathrm{Fe}_{3} \mathrm{O}_{4}$. It was conducive for a rapid solid-liquid separation between MMIC and the upper solution, especially under an applied magnetic field.

\section{Sedimentation behavior}

Figure 5 presented the sedimentation behaviors of MIC, MMIC, and MMIP in bottles after ultrasonically processed for $1 \mathrm{~min}$ and settled for $10 \mathrm{~min}$. The opaque solution above MMIC and MMIP became clear soon, while the upper solution kept opaque above MIC before and after sedimentation. MMIC and MMIP had a density far larger than MIC, thus MMIC and MMIP were far more readily to be settled in the bottom of the solution than MIC. Therefore, MMIC of a core-shell structure had a potential to be utilized as an adsorbent for a fast analysis of a target through a rapid solid-liquid phase separation.
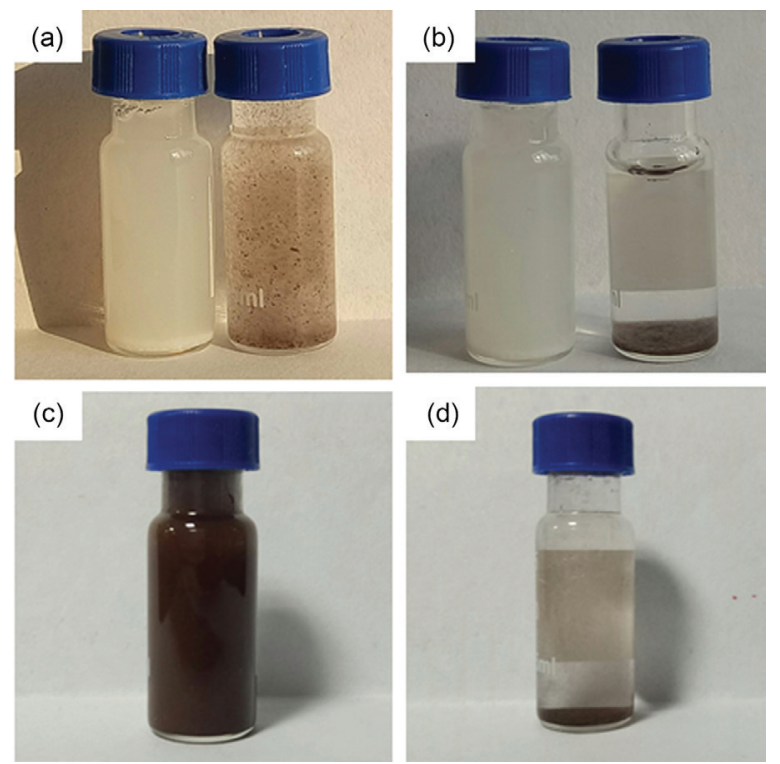

Figure 5. Photos of (a) MIC (left) and MMIC (right) before sedimentation; (b) MIC (left) and MMIC (right) 10 min after sedimentation; (c) MMIP before sedimentation; and (d) MMIP 10 min after sedimentation.

\section{Adsorption kinetics}

$10 \mathrm{mg}$ MMIC, MMIP, MNIC, and MNIP were put into four centrifuge tubes, each one containing $10 \mathrm{~mL}$ solutions of E2 $\left(80 \mathrm{mg} \mathrm{L}^{-1}\right)$. Figure 6 presented the adsorption quantity (Q) of E2 by MMIC, MMIP, MNIC and MNIP after 5, 10, 15, 20, 30, 40, 50, $60 \mathrm{~min}$. All experiments were performed in triplicate.

The adsorption quantity (Q) was calculated from the equation 1:

$$
\mathrm{Q}=\frac{\left(\mathrm{A}_{\mathrm{o}}-\mathrm{A}_{\mathrm{t}}\right) \times \mathrm{V}}{\mathrm{m}_{\mathrm{i}} \times \mathrm{A}_{\mathrm{o}}} \times \mathrm{c}_{\mathrm{o}}
$$

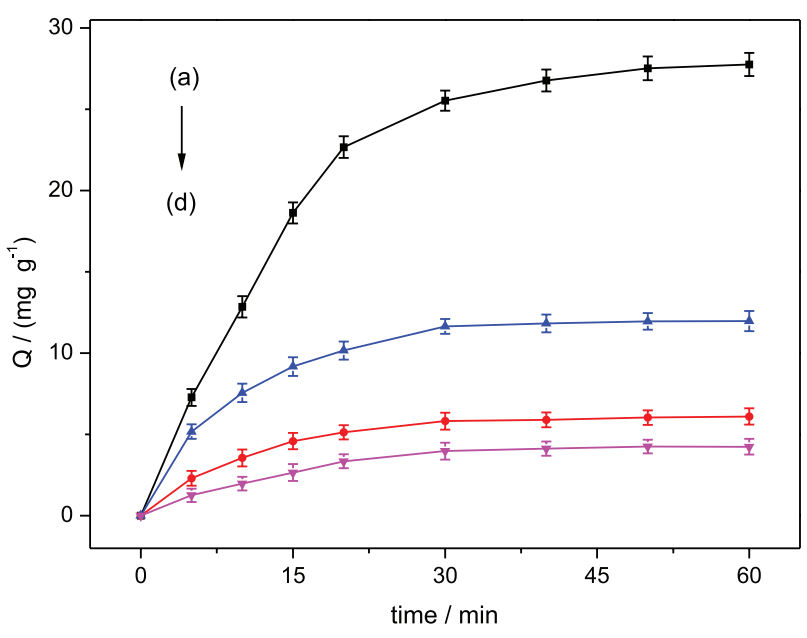

Figure 6. Adsorption isotherm of E2 by (a) MMIC; (b) MMIP; (c) MNIC; and (d) MNIP.

where $A_{o}$ is the initial absorbance of the sample solution; $A_{t}$ is the absorbance of the sample solution after adsorbed; $\mathrm{c}_{\mathrm{o}}$ is the initial concentration of the solution $\left(\mathrm{mg} \mathrm{mL}^{-1}\right)$; $\mathrm{V}$ is the volume of the solution $(\mathrm{mL}) ; \mathrm{m}_{\mathrm{i}}$ is the mass of dry adsorption materials ( $\mathrm{g}$ ).

With the increase of time, the adsorption of E2 by MMIC increased more sharply than by MMIP, and the equilibrium adsorption capacity of E2 by MMIC was nearly twice that of MMIP. This was because MMIC had a large specific surface area and an appropriate pore-size distribution, namely, the proper proportion of macro-, meso- and micro-pores, and there were specific recognition sites of E2 on the surface and inside the large holes of MMIC. Thus, MMIC had a higher density of adsorption sites than MMIP. Meanwhile, the structure of the MMIC surface was more loose (see Figures $2 \mathrm{~d}$ and $2 \mathrm{e}$ ), thus analyte molecules were more likely to come into contact with the specific sites of MMIC. Briefly, the specific interaction between E2 and imprinting sites on MMIC led to a shift of adsorption-desorption equilibrium for the adsorption. Consequently, MMIC had a higher adsorption capacity and a faster adsorption rate for E2 than MMIP.

MNIC had no specific recognition sites for E2, though it had a looser structure than MNIP. Thus there was only slightly increase of the adsorption of E2 by MNIC, compared to MNIP.

\section{The selectivity of MMIC for E2}

The selectivity of MMIC for E2 was verified by comparing the adsorption quantity of MMIC for E2 with that for estriol (E3), a structural analogue of E2.

As shown in Figure 7, it was carried out the adsorption of E2 or E3 alone by MMIC or MNIC individually. Meanwhile, the simultaneous adsorption of E2 and E3 by 
MMIC or MNIC in a mixed solution was conducted. All experiments were performed in triplicate.

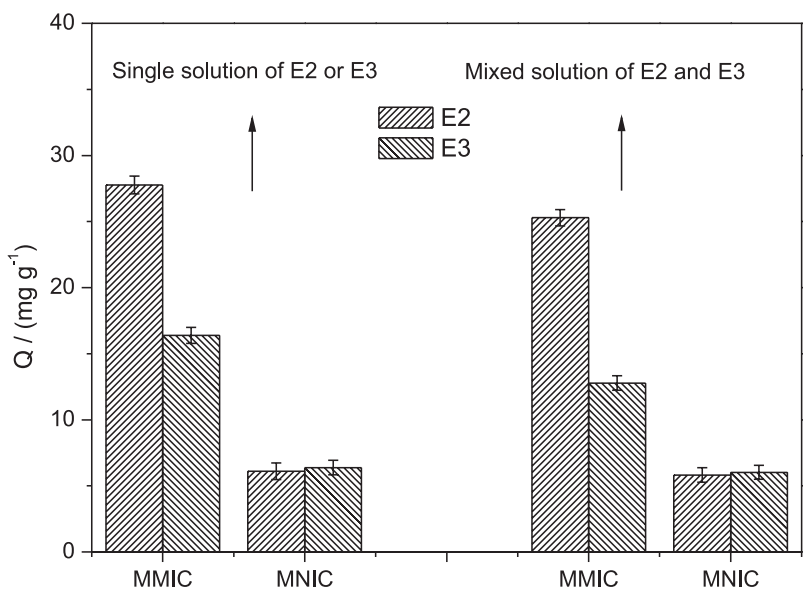

Figure 7. Adsorption selectivity for E2 and E3 by MMIC and MNIC.

When MMIC or MNIC adsorbed E2 and E3 solution individually, MMIC showed an adsorption capacity of E2 2.8 times that by MNIC. However, MMIC had an adsorption capacity of E3 15\% higher than that of MNIC. Meanwhile, MMIC has an adsorption capacity for E2 70.5\% higher than that for E3.

While MMIC or MNIC were placed in the mixed solution of E2 and E3, both adsorption for E2 and E3 decreased compared to that in their individual solution. The adsorption of E2 by MMIC reduced by $7.1 \%$, while the adsorption of E3 reduced by $21.5 \%$. The adsorption of E2 and E3 by MNIC reduced just slightly. ${ }^{3,10}$

\section{Chromatographic performances}

MMIC was packed in a $2 \mathrm{~cm}$ stainless steel column as stationary phase. Because $\mathrm{Fe}_{3} \mathrm{O}_{4} @$ MPS had a greater hardness than MAA, then a higher ratio of $\mathrm{Fe}_{3} \mathrm{O}_{4} @$ MPS to MAA in raw reactants resulted in a better pressure resistance of the prepared MMIC. With the increase of the ratio of $\mathrm{Fe}_{3} \mathrm{O}_{4} @$ MPS to MAA, the column pressure dropped gradually. When the ratio of $\mathrm{Fe}_{3} \mathrm{O}_{4} @$ MPS to MAA was 2:5, the imprinting factor $\left(\mathrm{I}_{\mathrm{f}}\right)$ for $\mathrm{E} 2$ by MMIC was the largest.

From Table S1 (Supplementary Information) we can find that the polarity of the mobile phase increased and $\mathrm{I}_{\mathrm{f}}$ for E2 by MMIC rose by 3.61 times with the increase of $\mathrm{H}_{2} \mathrm{O} \%(\mathrm{v} / \mathrm{v})$ in the mobile phase from 0 to $40 \%$. Acetone, chosen as a non-retention component for the determination of dead time, has a larger polarity than E2. Then the elution ability of acetone was enhanced slightly; while for E2, the elution ability reduced relatively. Thus, the capacity factor (k) for E2 by MMIC increased, while k for E2 by
MMIC did not nearly change at the meantime. Under the synergic impacts of the molecular imprinting effect and the enhancement of the polarity of mobile phase, the imprinting factor of E2 by MMIC increased significantly.

\section{Real sample analysis}

$5.00 \mathrm{~g}$ milk powder was placed in $45.00 \mathrm{~mL}$ of $\mathrm{H}_{2} \mathrm{O} / \mathrm{CH}_{3} \mathrm{CN}(1: 2 \mathrm{v} / \mathrm{v}) .3 .00 \mathrm{~g} \mathrm{NaCl}$ was placed in the solution, and the mixture was centrifuged for $10 \mathrm{~min}$ at $5000 \mathrm{rpm}$. After the supernatant was taken out from the centrifuge tube, $10.00 \mathrm{~mL} n$-hexane was added in it. The mixture was shaken for $1 \mathrm{~min}$ and kept still for $5 \mathrm{~min}$ (twice). Then $n$-hexane was removed and the lipid materials in milk powder were removed. The residual solution was dried, re-dissolved and capacitized to $5.00 \mathrm{~mL}$ with methanol. Finally, the E2-spiked solution of milk powder was prepared by adding $3.00 \mathrm{~mL}$ of above solution into $27.00 \mathrm{~mL}$ E2 standard solution $\left(25 \mathrm{mg} \mathrm{L}^{-1}\right)$.

MMIC and MNIC were put into the E2-spiked solution of milk powder. After the adsorption, the solution was filtered through $0.22 \mu \mathrm{m}$ membrane.

Each $20 \mu \mathrm{L}$ of solution was injected in $\mathrm{C}_{18}$ column $(150 \times 4.6 \mathrm{~mm}$, Inertsil $)$ and analyzed at $280 \mathrm{~nm}$ on DAD at a flow rate of $0.8 \mathrm{~mL} \mathrm{~min}{ }^{-1}\left(\mathrm{CH}_{3} \mathrm{OH}: \mathrm{H}_{2} \mathrm{O} 80: 20 \mathrm{v} / \mathrm{v}\right)$. From Figure 8, there were obvious signals of E2 (retention time $4.84 \mathrm{~min}$ ) in the spiked solution before extraction. The peak height of E2 was dropped sharply about 50\% after E2 in the spiked solution was extracted with MMIC, while just about $10 \%$ of the spiked E2 was extracted with MNIC. This indicates that MMIC possessed high enrichment capabilities and selectivity for E2 in milk powder.

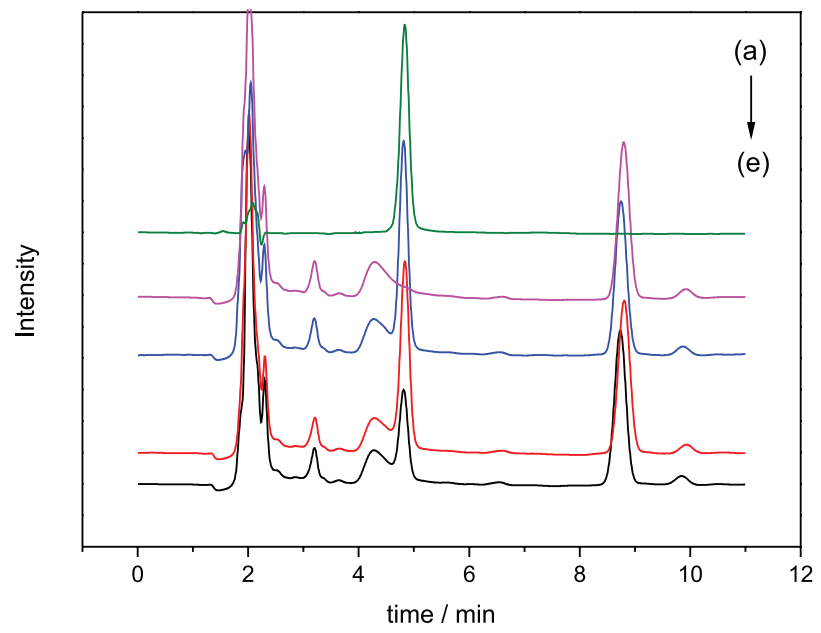

Figure 8. Chromatograms of (a) milk powder solution; (b) standard solution of E2; (c) E2-spiked solution of milk powder before extraction; (d) E2-spiked solution of milk powder after MNIC extraction; and (e) after MMIC extraction. 
Table 1. Performances of the analysis of E2 by HPLC (high-performance liquid chromatography) with MMIC and MMIP packed column

\begin{tabular}{|c|c|c|c|c|c|c|c|c|c|}
\hline \multirow[b]{2}{*}{ Sample } & \multirow{2}{*}{$\begin{array}{l}\text { Added / } \\
\left(\mathrm{ng} \mathrm{g}^{-1}\right)\end{array}$} & \multicolumn{2}{|c|}{ MMIP } & \multicolumn{2}{|c|}{ MNIP } & \multicolumn{2}{|c|}{ MMIC } & \multicolumn{2}{|c|}{ MNIC } \\
\hline & & $\begin{array}{c}\text { Found } \pm \\
\mathrm{SD} /\left(\mathrm{ng} \mathrm{g}^{-1}\right)\end{array}$ & $\begin{array}{c}\text { Recovery } \pm \\
\text { RSD / \% }\end{array}$ & $\begin{array}{c}\text { Found } \pm \\
\mathrm{SD} /\left(\mathrm{ng} \mathrm{g}^{-1}\right)\end{array}$ & $\begin{array}{c}\text { Recovery } \pm \\
\text { RSD / \% }\end{array}$ & $\begin{array}{c}\text { Found } \pm \\
\mathrm{SD} /\left(\mathrm{ng} \mathrm{g}^{-1}\right)\end{array}$ & $\begin{array}{c}\text { Recovery } \pm \\
\text { RSD / \% }\end{array}$ & $\begin{array}{c}\text { Found } \pm \\
\mathrm{SD} /\left(\mathrm{ng} \mathrm{g}^{-1}\right)\end{array}$ & $\begin{array}{c}\text { Recovery } \pm \\
\text { RSD / \% }\end{array}$ \\
\hline 1 & 10 & $9.06 \pm 0.3$ & $90.6 \pm 3.1$ & $2.75 \pm 0.1$ & $27.5 \pm 1.2$ & $9.78 \pm 0.2$ & $97.8 \pm 2.2$ & $2.45 \pm 0.2$ & $24.5 \pm 2.1$ \\
\hline 2 & 50 & $46.4 \pm 1.6$ & $92.8 \pm 3.3$ & $14.9 \pm 0.7$ & $29.8 \pm 1.4$ & $47.9 \pm 1.3$ & $96.2 \pm 2.8$ & $12.6 \pm 0.8$ & $25.2 \pm 1.6$ \\
\hline 3 & 100 & $92.2 \pm 4.9$ & $92.2 \pm 5.0$ & $29.6 \pm 3.1$ & $29.6 \pm 3.3$ & $96.5 \pm 4.3$ & $96.5 \pm 4.5$ & $25.7 \pm 3.3$ & $25.7 \pm 3.4$ \\
\hline
\end{tabular}

MMIP: magnetic molecularly imprinted polymer; MNIP: magnetic non-imprinted polymer; MMIC: magnetic molecularly imprinted cryogel; MNIC: magnetic non-imprinted cryogel; SD: standard deviation; RSD: relative standard deviation.

Table 2. Comparison of LOD of E2 by various methods

\begin{tabular}{|c|c|c|c|c|c|}
\hline Sample & Pretreatment method & Assay method & LOD & Recovery / \% & Reference \\
\hline Water & $\mathrm{C}_{18}-\mathrm{SPE}$ & HPLC-UV & $41.0-240.0 \mu \mathrm{g} \mathrm{L}^{-1}$ & $60-101$ & 52 \\
\hline Milk, milk powder & SPME & HPLC-UV & $4.3-7.5 \mathrm{ng} \mathrm{mL}^{-1}$ & $72.6-94.5$ & 53 \\
\hline Milk & d-SPE & RAM-MMIP-HPLC-UV & $4.7-10.5 \mathrm{ng} \mathrm{g}^{-1}$ & $85.2-98.6$ & 54 \\
\hline Milk & SPE & HPLC-UV & $4-6 \mathrm{ng} \mathrm{g}^{-1}$ & $84.1-93.5$ & 55 \\
\hline Fish and prawn & MIPs-SPE & HPLC-FL & $23.0 \mu \mathrm{g} \mathrm{L}^{-1}$ & $78.3-84.5$ & 56 \\
\hline Milk powder & MMIC-SPE & HPLC-UV & $0.8-1.2 \mathrm{ng} \mathrm{g}^{-1}$ & $92-101$ & this work \\
\hline
\end{tabular}

LOD: limit of detection; SPE: solid phase extraction; SPME: solid phase microextraction; d-SPE: dispersive solid phase extraction; MIP: molecularly imprinted polymer; MMIC: magnetic molecularly imprinted cryogel; HPLC-UV: high-performance liquid chromatography-ultraviolet; RAM: restricted access media; HPLC-FL: high-performance liquid chromatography-fluorescence detection.

From Table 1, the recoveries and RSD of E2 from the spiked solution of real milk powder (10,50 and $\left.100 \mathrm{ng} \mathrm{g}^{-1}\right)$ after extraction by MMIC were $92-101 \%$ and $2.2-4.5 \%$ $(n=3)$, respectively. Meanwhile, the recoveries and RSD of E2 after extraction by MMIP from the spiked real samples were $87.2-97.2 \%$ and 3.1-5.0\% $(n=3)$, respectively. Both the recoveries and RSD for the extraction of E2 using MMIC were better than using MMIP.

Different methods for determining E2 were summarized briefly in Table 2 . The present approach had a limit of detection (LOD) for E2 0.8-1.2 $\mathrm{ng} \mathrm{g}^{-1}(\mathrm{~S} / \mathrm{N} 3)$, which was lower than those reported by other methods. The present method could be utilized to detect E2 in milk powder with a satisfactory result owing to the relatively lower LOD and $\mathrm{RSD}$, as well as higher recoveries.

\section{Conclusion}

An E2-templated MMIC was prepared with MAA as monomer, EGDMA as crosslinker at $-20^{\circ} \mathrm{Con} \mathrm{Fe}_{3} \mathrm{O}_{4} @ \mathrm{MPS}$ microparticles. The diameter of the prepared MMIC particle was uniformly around three times as that of $\mathrm{Fe}_{3} \mathrm{O}_{4} @ \mathrm{SiO}_{2}$.

MMIC had a higher adsorption capacity and a better recognition for E2 than MMIP. Meanwhile, MMIC showed good chromatographic properties as for the pressure of the packed column. The $\mathrm{I}_{\mathrm{f}}$ for $\mathrm{E} 2$ as to acetone by MMIC packed column was the largest under a mass ratio of $\mathrm{Fe}_{3} \mathrm{O}_{4} @$ MPS to MAA 2:5 in raw materials.

In the analysis of $\mathrm{E} 2$ in the milk powder through MMIC based SPE-HPLC, the LOD was $0.8 \mathrm{ng} \mathrm{g}^{-1}(\mathrm{~S} / \mathrm{N} 3)$ at spiked levels of 10,50 and $100 \mathrm{ng} \mathrm{g}^{-1}$, which was lower than that using the conventional methods. The recoveries and RSD of E2 in the spiked samples were $92-101 \%$ and $2.2-4.5 \%$ $(n=3)$, respectively.

\section{Supplementary Information}

Supplementary information is available free of charge at http://jbcs.sbq.org.br.

\section{Acknowledgments}

This work was financially supported by China NSFC (No. 21375115), and the Priority Academic Program Development of Jiangsu Higher Education Institutions.

\section{References}

1. Wu, X.; Li, Y. R.; Zhu, X. L.; He, C. Y.; Wang, Q.; Liu, S. R.; Talanta 2017, 162, 57.

2. Zarei, A. R.; Zafarghandi, R. S.; J. Braz. Chem. Soc. 2015, 26, 741. 
3. Madrakian, T.; Afkhami, A.; Mahmood-Kashani, H.; Ahmadi, M.; Talanta 2013, 105, 255.

4. Hajizadeh, S.; Xu, C. G.; Kirsebom, H.; Ye, L.; Mattiasson, B.; J. Chromatogr. A 2013, 1274, 6.

5. Shi, H. L.; Peng, S. L.; Sun, J.; Liu, Y. M.; Zhu, Y. T.; Qing, L. S.; Liao, X.; J. Sep. Sci. 2014, 37, 704.

6. Martin, M.; Salazar, P.; Villalonga, R.; Campuzano, S.; Pingarron, J. M.; Gonzalez-Mora, J. L.; J. Mater. Chem. B 2014, 2,739 .

7. Martin, M.; Orive, A. G.; Lorenzo-Luis, P.; Creus, A. H.; Gonzalez-Mora, J. L.; Salazar, P.; ChemPhysChem 2014, 15, 3742 .

8. Azodi-Deilami, S.; Abdouss, M.; Asadi, E.; Najafabadi, A. H.; Sadeghi, S.; Farzaneh, S.; Asadi, S.; J. Appl. Polym. Sci. 2014, 131, 41209.

9. Gao, R.; Mu, X.; Zhang, J.; Tang, Y.; J. Mater. Chem. B 2014, $2,783$.

10. Zengin, A.; Yildirim, E.; Tamer, U.; Caykara, T.; Analyst 2013, 138, 7238 .

11. Socas-Rodriguez, B.; Hernandez-Borges, J.; Salazar, P.; Martin, M.; Rodriguez-Delgado, M. A.; J. Chromatogr. A 2015, 1397, 1.

12. Rios, A.; Zougagh, M.; Bouri, M.; Anal. Methods 2013, 5, 4558.

13. Xie, L. J.; Jiang, R. F.; Zhu, F.; Liu, H.; Ouyang, G. F.; Anal. Bioanal. Chem. 2014, 406, 377.

14. Li, Q. L.; Lam, M. H. W.; Wu, R. S. S.; Jiang, B. W.; J. Chromatogr. A 2010, 1217, 1219.

15. Huang, H. Y.; Lin, C. L.; Wu, C. Y.; Cheng, Y. J.; Lin, C. H.; Anal. Chim. Acta 2013, 779, 96.

16. Cychosz, K. A.; Ahmad, R.; Matzger, A. J.; Chem. Sci. 2010, 1, 293.

17. Zhu, Y. X.; Zhou, C. R.; Qin, S. S.; Ren, Z. Y.; Zhang, L. Y.; Fu, H. G.; Zhang, W. B.; Electrophoresis 2012, 33, 340.

18. Yan, Z. M.; Zheng, J. N.; Chen, J. F.; Tong, P.; Lu, M. H.; Lin, Z.; Zhang, L.; J. Chromatogr. A 2014, 1366, 45.

19. Qin, W. W.; Silvestre, M. E.; Kirschhöfer, F.; Brenner-Weiss, G.; Franzreb, M.; J. Chromatogr. A 2015, 1411, 77.

20. He, L.; Gielen, G.; Bolan, N. S.; Zhang, X.; Qin, H.; Huang, H.; Wang, H.; Agron. Sustainable Dev. 2015, 35, 519.

21. Lan, H. Z.; Gan, N.; Pan, D. D.; Hu, F. T.; Li, T. H.; Long, N. B.; Qiao, L.; J. Chromatogr. A 2014, 1331, 10.

22. Denizli, A.; Say, R.; Pişkin, E.; React. Funct. Polym. 2003, 55 , 99.

23. Cetin, K.; Denizli, A.; Colloids Surf. B 2015, 126, 401.

24. Yang, C.; Zhou, X. L.; Liu, Y. R.; Zhang, Y.; Wang, J.; Tian, L. L.; Yan, Y. N.; Chin. J. Anal. Chem. 2016, 44, 1322.

25. Unluer, O. B.; Ersoz, A.; Denizli, A.; Demirel, R.; Say, R.; J. Chromatogr. B 2013, 934, 46.

26. Yang, C.; Zhou, X. L.; Liu, Y. R.; Wang, J.; Tian, L. L.; Zhang, Y.; Hu, X. Y.; J. Appl. Polym. Sci. 2016, 133, 1.
27. Wang, Y.; Li, N.; Chem. Ind. Eng. Prog. (Beijing, China) 2010, 29, 2315.

28. Yang, C.; Liu, G. F.; Zhou, X. L.; Liu, Y. R.; Wang, J.; Tian, L. L.; Hu, X. Y.; Wang, Y. Y.; Catal. Lett. 2015, 145, 1778.

29. Zhang, C.; Jia, X.; Wang, Y.; Zhang, M.; Yang, S.; Guo, J.; J. Sep. Sci. 2014, 37, 419.

30. Onnby, L.; Pakade, V.; Mattiasson, B.; Kirsebom, H.; Water Res. 2012, 46, 4111.

31. Yang, C.; Luan, X.; Zhao, M.; Liu, G.; Wang, J.; Qu, Q.; Hu, X.; Electrophoresis 2013, 34, 1383.

32. Asliyuce, S.; Uzun, L.; Say, R.; Denizli, A.; React. Funct. Polym. 2013, 73, 813.

33. Qiao, L.; Gan, N.; Hu, F.; Wang, D.; Lan, H.; Li, T.; Wang, H.; Microchim. Acta 2014, 181, 1341.

34. Marques, R.; Vaz, F. A. S.; Polonini, H. C.; de Oliveira, M. A. L.; J. Braz. Chem. Soc. 2015, 26, 609.

35. Peng, H. L.; Luo, M.; Xiong, H.; Yu, N. X.; Ning, F. J.; Fan, J. P.; Zeng, Z. L.; Li, J. H.; Chen, L. X.; J. Chromatogr. A 2016, 1442,1 .

36. Li, Y.; Zhang, C.; Liu, J. L.; Li, X. P.; Wang, X. J.; Chem. J. Chin. Univ. 2013, 34, 634.

37. Xie, G. J.; Jiang, L. Y.; Chen, J. M.; Chin. J. Soil Sci. 2008, 39 , 182.

38. Gail, M. H.; Fears, T. R.; Hoover, R. N.; Chandler, D. W.; Donaldson, J. L.; Hyer, M. B.; Pee, D.; Ricker, W. V.; Siiteri, P. K.; Stanczyk, F. Z.; Vaught, J. B.; Ziegler, R. G.; Cancer Epidemiol., Biomarkers Prev. 1996, 5, 835.

39. Cesen, M.; Heath, E.; Sci. Total Environ. 2017, 590, 832.

40. Zhu, W.; Liu, Y.; Yuan, P.; Yang, J.; Chin. J. Chromatogr. 2010, 28, 1031.

41. Barreiro, R.; Regal, P.; Diaz-Bao, M.; Fente, C. A.; Cepeda, A.; Foods 2015, 4, 605.

42. Ni, X.; Xia, B.; Wang, L. M.; Ye, J.; Du, G. S.; Feng, H. W.; Zhou, X. T.; Zhang, T.; Wang, W. H.; Anal. Biochem. 2017, $523,17$.

43. Albuquerque, C. D. L.; Nogueira, R. B.; Poppi, R. J.; Microchem. J. 2016, 128, 95.

44. Ben Sghaier, R.; Net, S.; Ghorbel-Abid, I.; Bessadok, S.; Le Coz, M.; Hassan-Chehimi, D. B.; Trabelsi-Ayadi, M.; Tackx, M.; Ouddane, B.; Water, Air, Soil Pollut. 2017, 228, 2.

45. Goh, S. X. L.; Duarah, A.; Zhang, L. F.; Snyder, S. A.; Lee, H. K.; J. Chromatogr. A 2016, 1465, 9.

46. de Amorim, K. P.; Andrade, L. S.; Anal. Methods 2017, 9, 1627.

47. Iparraguirre, A.; Navarro, P.; Rodil, R.; Prieto, A.; Olivares, M.; Etxebarria, N.; Zuloaga, O.; J. Chromatogr. A 2014, 1356, 163.

48. Luo, X. L.; Li, G. K.; Hu, Y. F.; Talanta 2017, 165, 377.

49. Qiu, X. Z.; Wu, Y.; Chen, D. Z.; Lai, L. Y.; Liang, Y.; Guo, H. S.; J. Nanosci. Nanotechnol. 2016, 16, 12374.

50. Liu, J. Y.; Lu, W. H.; Liu, H. T.; Wu, X. Q.; Li, J. H.; Chen, L. X.; Electrophoresis 2016, 37, 2502. 
51. Zou, Y.; Li, Y. H.; Jin, H.; Zou, D. Q.; Liu, M. S.; Yang, Y. L.; J. Braz. Chem. Soc. 2012, 23, 694.

52. Stafiej, A.; Pyrzynska, K.; Regan, F.; J. Sep. Sci. 2007, 30, 985.

53. Tian, M. M.; Feng, W.; Ye, J. J.; Jia, Q.; Anal. Methods 2013, 5,3984 .

54. Lv, Y. K.; He, Y. D.; Xiong, X.; Wang, J. Z.; Wang, H. Y.; Han, Y. M.; New J. Chem. 2015, 39, 1792.
55. Liu, H. C.; Zou, Y. H.; Li, Q. W.; Zhu, E.; Chin. J. Anal. Chem. 2008, 36, 245.

56. Jiang, T. H.; Zhao, L. X.; Chu, B. L.; Feng, Q. H.; Yan, W.; Lin, J. M.; Talanta 2009, 78, 442.

Submitted: April 7, 2017 Published online: June 7, 2017 